\title{
Hubungan Konsumsi Makanan Manis sebagai Faktor Risiko Terjadinya Gangguan Pemusatan Perhatian dan Hiperaktivitas pada Anak di 9 Sekolah Dasar Kota Manado
}

\author{
Pearensia E. P. Hidayat, ${ }^{1}$ Theresia M. D. Kaunang, ${ }^{2}$ Anita E. Dundu \\ ${ }^{1}$ Kandidat Skripsi Fakultas Kedokteran Universitas Sam Ratulangi Manado \\ ${ }^{2}$ Bagian Ilmu Kedokteran Jiwa Fakultas Kedokteran Universitas Sam Ratulangi Manado \\ Email: putriacey@gmail.com
}

\begin{abstract}
Attention-deficit/hyperactivity disorder (ADHD) is one of the most common psychiatric disorders in childhood and can be associated with sweetened food consumption. This study was aimed to determine the prevalence of ADHD children and the association between sweetened food consumption and children in nine elementary schools in Manado. This was an analytical study with a cross-sectional design. Samples were students of elementary schools that represented nine districts in Manado and were randomly selected using the multi-stage random sampling technique. The results showed that there wre $20.1 \%$ of elementary school students in Manado that had ADHD. Statistical analysis obtained a p-value of $0.000(<0.05)$ and $\mathrm{OR}(\mathrm{CI} 95 \%)=23.61(\mathrm{OR}>1)$. In conclusion, the prevalence of ADHD children in Manado was still high and there was a positive correlation between sweetened food consumption as a risk factor of children with ADHD in elementary schools in Manado.
\end{abstract}

Keywords: ADHD, sweetened food consumption, elementary school student

\begin{abstract}
Abstrak: Gangguan pemusatan perhatian dan hiperaktivitas (GPPH) adalah salah satu gangguan psikiatri anak yang paling sering dan dihubungkan dengan konsumsi makanan manis. Penelitian ini bertujuan untuk mengetahui prevalensi GPPH pada anak dan hubungan konsumsi makanan manis sebagai faktor risiko terjadinya GPPH pada anak di sembilan sekolah dasar di Kota Manado. Jenis penelitian ialah analitik dengan desain potong lintang. Sampel yang digunakan ialah siswa Sekolah Dasar yang mewakili sembilan Kecamatan di Kota Manado yang dipilih secara acak dengan teknik multi stage random sampling. Penelitian dilakukan dengan uji asosiasi Fisher Exact. Hasil penelitian mendapatkan 20,1\% anak Sekolah Dasar di Kota Manado menyandang GPPH. Hasil analisis data mendapatkan nilai $\mathrm{p}=0,000$ $(<0,05)$ dan $\mathrm{OR}=23,61(\mathrm{OR}>1)$. Simpulan penelitian ini ialah angka kejadian GPPH di Manado cukup tinggi dan terdapat hubungan positif antara seringnya mengonsumsi makanan manis sebagai faktor risiko terjadinya GPPH pada anak.
\end{abstract}

Kata kunci: GPPH, makanan manis, anak sekolah dasar

\section{PENDAHULUAN}

Anak merupakan individu di bawah usia 18 tahun yang merupakan aset dan generasi penerus bangsa karena anak yang akan menentukan masa depan bangsa dan negara Indonesia. ${ }^{1}$ Perkembangan anak merupakan proses berkelanjutan dalam memperoleh keterampilan yang baru dan lebih lanjut yang bergantung pada pema- tangan sistem saraf. ${ }^{2}$

Gangguan pemusatan perhatian dan hiperaktivitas (GPPH) merupakan salah satu gangguan psikiatri yang paling sering terjadi pada anak. ${ }^{3}$ Sekitar $5-8 \%$ anak usia sekolah mengalami GPPH; 60-85\% di antaranya masih memenuhi kriteria untuk GPPH pada saat remaja dan $60 \%$ hingga dewasa. ${ }^{4}$ Prevalensi GPPH pada anak di 
Amerika Serikat adalah $8.4 \% .^{5}$ Penelitian terbatas yang dilakukan di Jakarta, Indonesia melaporkan kejadian GPPH sebanyak $4,2 \%$ dan paling banyak ditemukan pada anak laki-laki dibandingkan anak perempuan. $^{5-7}$

Gejala GPPH dapat bertahan hingga usia dewasa sebanyak $78 \%$ dan dapat menyebabkan hal yang buruk seperti nilai akademik yang rendah karena susah memusatkan perhatian, kesulitan berinteraksi sosial dengan teman sebaya, pendapatan seumur hidup berkurang, dan peningkatan risiko bunuh diri karena depresi. Gangguan pemusatan perhatian dan hiperaktivitas sering disertai dengan gangguan dalam bidang akademik, pekerjaan, sosial, kepribadian, dimana yang paling buruk dapat menyebabkan gangguan kepribadian antisosial pada anak. Gangguan jenis ini sangat memengaruhi kualitas hidup dari anak, orang tua, dan saudara, dimana dapat menimbulkan biaya ekonomi yang tinggi dan beban jangka panjang bagi keluarga dan masyarakat. ${ }^{8-11}$

Penyebab GPPH sampai saat ini belum diketahui secara pasti, namun ada beberapa faktor diperkirakan dapat menyebabkan kejadian GPPH pada anak yaitu faktor neuroanatomi, faktor lingkungan, dan faktor psikososial. ${ }^{5}$ Konsumsi makanan manis (simple sugar) sering dikatakan sebagai salah satu faktor kontribusi neuroanatomi dan neurokimiawi penyebab GPPH pada anak, dimana gula sering dikaitkan dengan dopaminergik, namun belum ada studi yang pasti dengan hal ini karena kurangnya penelitian tentan ini. ${ }^{4}$

Makanan yang mengandung gula sering dijumpai dalam kehidupan seharihari seperti permen, makanan ringan, biscuit, wafer, dan juga minuman manis. Makanan seperti ini sangat digemari oleh anak-anak usia sekolah. Konsumsi makanan yang mengandung gula dapat menyebabkan masalah perilaku karena menyebabkan intoleransi gula, hipoglikemi, dan pengurangan konsumsi makanan bergizi lain sehingga banyak dihubungkan dengan terjadinya hiperaktivitas pada anak. ${ }^{12}$

Pada anak-anak dan dewasa, WHO merekomendasikan untuk mengonsumsi gula dibawah $10 \%$ dari total asupan energi, namun di Inggris, anak-anak telah melebihi jumlah asupan gula maksimum yang disarankan untuk anak yang berusia 18 tahun pada saat mereka berumur 10 tahun. ${ }^{13}$ Park et $\mathrm{al}^{14}$ menyatakan bahwa konsumsi tinggi makanan manis berhubungan dengan terjadinya GPPH pada anak, namun penelitian dari $\mathrm{Yu}^{15}$ tidak menemukan adanya bukti bahwa konsumsi makanan manis dengan kejadian GPPH pada anak.

Berdasrkan uraian yang telah dipaparkan maka penulis tertarik untuk mengetahui hubungan konsumsi makanan manis sebagai faktor risiko terjadinya GPPH pada anak Sekolah Dasar Kota Manado

\section{METODE PENELITIAN}

Jenis penelitian yang digunakan ialah analitik dengan desain potong lintang. Pada pengambilan sampel digunakan total sampling dan multi-stage sampling dengan populasi anak usia sekolah dasar, guru, dan orangtua dari anak tersebut di 9 Sekolah Dasar di 9 Kecamatan di Kota Manado.

\section{HASIL PENELITIAN}

Jumlah sampel yang diperoleh yaitu 184 anak untuk prevalensi GPPH. Terdapat $37(20,1 \%)$ anak memiliki GPPH dengan perbandingan yaitu 26 anak laki-laki (70,3\%) dan 11 anak perempuan (29,7\%).

Berdasarkan kuesioner dan wawancara terdapat 165 anak yang sesuai dengan kriteria inklusi dan eksklusi. Tabel 1 memperihatkan responden terbanyak ialah anak perempuan yaitu 85 anak dan kemudian anak laki-laki sebanyak 80 anak.

Tabel 1. Distribusi responden berdasarkan jenis kelamin

\begin{tabular}{ccc}
\hline Jenis kelamin & Jumlah & Persentase \\
\hline Laki-laki & 80 & 48,5 \\
Perempuan & 85 & 51,5 \\
Total & 165 & 100 \\
\hline
\end{tabular}

Tabel 2 memperlihatkan responden dengan GPPH terdiri dari 26 anak laki-laki dan 11 anak perempuan. 
Tabel 2. Distribusi responden dengan GPPH berdasarkan jenis kelamin

\begin{tabular}{ccc}
\hline Jenis kelamin & Jumlah & Persentase \\
\hline Laki-laki & 26 & 70 \\
Perempuan & 11 & 30 \\
Total & 37 & 100 \\
\hline
\end{tabular}

Tabel 3 memperlihatkan responden terbanyak ialah anak berusia 7 tahun yaitu sebanyak 58 anak, sedangkan yang paling sedikit ialah anak yang berusia 11 tahun yaitu sebanyak 1 anak saja.

Tabel 3. Distribusi responden menurut usia

\begin{tabular}{ccc}
\hline $\begin{array}{c}\text { Usia } \\
\text { (tahun) }\end{array}$ & Jumlah & Persentase \\
\hline 6 & 2 & 1,21 \\
7 & 58 & 35,15 \\
8 & 39 & 23,64 \\
9 & 57 & 34,55 \\
10 & 8 & 4,84 \\
11 & 1 & 0,61 \\
Total & 165 & 100 \\
\hline
\end{tabular}

Tabel 4 memperlihatkan responden dengan GPPH terbanyak ialah anak berusia 9 tahun yaitu 13 anak sedangkan yang paling sedikit ialah anak yang berusia 6 tahun dan 11 tahun, masing-masing 1 anak.

Tabel 4. Distribusi responden dengan GPPH menurut usia

\begin{tabular}{ccc}
\hline $\begin{array}{c}\text { Usia } \\
\text { tahun) }\end{array}$ & Jumlah & Persentase \\
\hline 6 & 1 & 2,70 \\
7 & 12 & 32,43 \\
8 & 6 & 16,22 \\
9 & 13 & 35,14 \\
10 & 4 & 10,81 \\
11 & 1 & 2,70 \\
Total & 165 & 100 \\
\hline
\end{tabular}

Tabel 5 memperlihatkan responden terbanyak duduk di kelas 4 yaitu 69 anak sedangkan responden yang paling sedikit duduk di kelas 3 yaitu 35 anak.
Tabel 6 memperlihatkan responden dengan GPPH terbanyak duduk di kelas 4 yaitu 18 anak sedangkan responden yang paling sedikit duduk di kelas 3 yaitu 5 anak.

Tabel 5. Distribusi responden menurut kelas

\begin{tabular}{ccc}
\hline Kelas & Jumlah & Persentase \\
\hline Kelas 2 & 61 & 37 \\
Kelas 3 & 35 & 21 \\
Kelas 4 & 69 & 42 \\
Total & 165 & 100 \\
\hline
\end{tabular}

Tabel 6. Distribusi responden dengan GPPH menurut kelas

\begin{tabular}{ccc}
\hline Kelas & Jumlah & Persentase \\
\hline Kelas 2 & 14 & 37,84 \\
Kelas 3 & 5 & 13,51 \\
Kelas 4 & 18 & 48,65 \\
Total & 37 & 100 \\
\hline
\end{tabular}

Tabel 7 memperlihatkan responden terbanyak ialah beragama Kristen yaitu 142 anak sedangkan responden yang paling sedikit ialah yang beragama Buddha yaitu 1 anak, Kong Hu Chu sebanyak 1 anak; tidak ada anak yang beragama Hindu.

Tabel 7. Distribusi responden menurut agama

\begin{tabular}{ccc}
\hline Agama & Jumlah & Persentase \\
\hline Kristen & 142 & 86 \\
Katolik & 18 & 11 \\
Islam & 3 & 1,8 \\
Buddha & 1 & 0,6 \\
Konghucu & 1 & 0,6 \\
Hindu & 0 & 0,0 \\
Total & 165 & 100 \\
\hline
\end{tabular}

Tabel 8 memperlihatkan responden terbanyak berasal dari suku Minahasa yaitu 102 anak dan masing-masing sebanyak 1 anak berasal dari suku Borneo, Saluan, Ambon, Timor, Bangka, NTT, dan Poso.

Tabel 9 memperlihatkan anak yang sering mengonsumsi makanan manis sebanyak 22 anak. 
Tabel 8. Distribusi responden menurut suku

\begin{tabular}{ccc}
\hline Suku & Jumlah & Persentase \\
\hline Minahasa & 102 & 62 \\
Gorontalo & 3 & 1,8 \\
Sanger & 32 & 19,4 \\
Siau & 3 & 1,8 \\
Jawa & 3 & 1,8 \\
Bantik & 2 & 1,2 \\
Tionghoa & 2 & 1,2 \\
Borneo & 1 & 0,6 \\
Toraja & 5 & 3 \\
Saluan & 1 & 0,6 \\
Banggai & 3 & 1,8 \\
Ambon & 1 & 0,6 \\
Timor & 1 & 0,6 \\
Talaud & 3 & 1,8 \\
Bangka & 1 & 0,6 \\
NTT & 1 & 0,6 \\
Poso & 1 & 0,6 \\
Total & 165 & 100 \\
\hline
\end{tabular}

Tabel 9. Distribusi responden menurut seringnya mengonsumsi makanan manis

\begin{tabular}{ccc}
\hline $\begin{array}{c}\text { Konsumsi } \\
\text { makanan } \\
\text { manis }\end{array}$ & Jumlah & Persentase \\
\hline Sering & 22 & 13,3 \\
Tidak sering & 143 & 86,7 \\
Total & 37 & 100 \\
\hline
\end{tabular}

Terdapat 22 anak sering mengonsumsi makanan manis; 17 di antaranya memiliki GPPH dan 5 anak tidak mengalami GPPH, sedangkan responden yang tidak sering mengonsumsi makanan manis sebanyak 143 orang; 18 anak dengan GPPH dan 143 anak tidak mengalami GPPH.

Tabel 10 menunjukkan hasil uji uji Fisher Exact yang mendapatkan nilai $\mathrm{p}=0,00 \quad(\mathrm{p}<0,05)$ dengan Odds Ratio CI (Confidence Intervals) 95\% sebesar 23,61 atau $\mathrm{OR}>1$ ).

\section{BAHASAN}

Pada penelitian ini, sebagian besar anak-anak yang menjadi responden berada di kelas 4 (42\%) dan paling banyak berusia 7 tahun dan 9 tahun (35\%). Teman sebaya mempunyai peran yang besar dalam perkembangan sosial dan emosional anakanak. Mereka dapat saling membantu untuk mengembangkan hobi mereka dan hal positif lainnya. Selain itu anak-anak sering mengikuti trend yang ada, seperti membeli mainan baru atau memakan makanan manis. Mereka ingin disukai dan mereka khawatir apabila akan ditinggalkan teman sebaya mereka. ${ }^{16}$

Mayoritas suku dari responden penelitian ini ialah suku Minahasa yang merupakan mayoritas suku di Kota Manado. Agama Kristen juga merupakan agama yang paling banyak dianut responden penelitian ini.

Berdasarkan penelitian yang dilakukan di 9 Kecamatan di Kota Manado, dari 184 anak yang diteliti terdapat 37 anak (20,1\%) yang mengalami GPPH. Sekitar 5$8 \%$ anak di dunia mengalami GPPH. ${ }^{4}$ Penelitian yang dilakukan Lalusu $^{17}$ di Kecamatan Wenang, Manado menunjukkan hasil yang lebih tinggi yaitu $27,1 \%$ anak usia Sekolah Dasar mengalami GPPH. Hasil yang sama juga didapatkan oleh Cornejo et al $^{18}$ di Amerika Serikat yaitu 20,4\% anak berusia 4-17 tahun mengalami GPPH. Hal yang sangat berbeda didapatkan oleh Yoo et $\mathrm{al}^{19}$ di Korea yang mendapatkan hanya 0,9\% anak usia 7-12 tahun yang mengalami GPPH.

Tabel 10. Tabulasi silang antara sering konsumsi makanan manis dengan terjadinya GPPH

\begin{tabular}{ccccc}
\hline \multirow{2}{*}{$\begin{array}{c}\text { Konsumsi makanan } \\
\text { manis }\end{array}$} & \multicolumn{3}{c}{ GPPH } & \\
\cline { 2 - 4 } & Ya & Tidak & Total & Nilai p \\
& F & F & F & \\
\hline Sering & 17 & 5 & 22 & 0,00 \\
Tidak sering & 18 & 125 & 143 & 0,00 \\
Total & 35 & 130 & 165 & OR $=23,61$ \\
\hline
\end{tabular}


Berdasarkan jenis kelamin, laki-laki lebih sering mengalami GPPH dibanding perempuan dengan rasio 5:1> Pada penelitian ini didapatkan $70,3 \%$ untuk anak laki-laki dan $29,7 \%$ untuk anak perempuan.

Berdasarkan hasil penelitian pada 165 anak yang memenuhi kriteria inklusi dan eksklusi, didapatkan 22 anak sering mengonsumsi makanan manis. Konsumsi makanan manis yang tinggi pada anak-anak sering dikaitkan dengan perilaku yang hiperaktif, dan menurut penelitian terjadi perbaikan perilaku pada anak-anak dengan GPPH yang dilakukan elimination diet. ${ }^{20}$

Hasil penelitian menggunakan uji chi square tidak bisa dilakukan karena nilai expected count yang kurang dari lima $(25 \%)$, sehingga digunakan uji alternatif. Uji analisis yang dilakukan pada penelitian ini ialah uji Fisher Exact yang mendapatkan nilai $\mathrm{p}=0,00<0,05$ dengan hasil OR (CI 95\%) ialah 23,61 (OR>1 yuang menunjukkan terdapat hubungan positif antara konsumsi makanan manis sebagai faktor risiko terjadi GPPH.

Menurut beberapa penelitian yang telah dilakukan sebelumnya dikatakan bahwa perilaku destruktif-agresif dan gelisah secara bermakna berkorelasi dengan jumlah gula yang dikonsumsi sehingga bisa dikatakan bahwa semakin banyak konsumsi gula seseorang, semakin buruk perilakunya. ${ }^{21} \mathrm{Hal}$ ini sesuai dengan penelitian yang dilakukan oleh Ching et al $^{10}$ yang menyatakan bahwa konsumsi makanan manis dapat menjadi salah satu faktor risiko yang tinggi atas terjadinya GPPH. Menurut penelitian dari Azadbakht et al, ${ }^{22}$ anak-anak dengan pola diet manis yang tinggi mempunyai peluang lebih besar untuk mengalami GPPH dengan OR (CI 95\%) 3,95. ${ }^{2}$

\section{SIMPULAN}

Prevalensi GPPH pada anak usia sekolah dasar di Kota Manado cukup tinggi yaitu $20,1 \%$. Terdapat hubungan positif antara terjadinya GPPH dengan sering mengonsumsi makanan manis yang merupakan salah satu faktor risiko terjadinya GPPH.

\section{Konflik Kepentingan}

Penulis menyatakan tidak terdapat konflik kepentingan dalam studi ini.

\section{DAFTAR PUSTAKA}

1. Kemenkes RI. Infodatin: Kondisi Pencapaian Program Kesehatan Anak Indonesia. Jakarta: Kementerian Kesehatan RI Pusat Data dan Informasi; 2014.

2. Reimschisel T. Global development delay and regression. In: Daroff $\mathrm{R}$, Jankovic J, Mazziotta J, Pomeroy S, editors. Bradley's Neurology in Clinical Practice (7th ed). Philadelphia: Elsevier, 2015; p. 66-72.

3. Wiguna T. Gangguan pemusatan perhatian dan hiperaktivitas. In: Elvira SD, Hadisukanto $\mathrm{G}$, editors. Buku Ajar Psikiatri. (2nd ed). Jakarta: FKUI, 2013; p. 48397.

4. Sadock BJ, Sadock VA, Ruiz P. Kaplan \& Sadock's Synopsis of Psychiatry: Behavioral Sciences/Clinical Psychiatry (11th ed). Philadelphia: Lippincott Wolters Kluwer, 2015; p. 1169-81.

5. Adiputra I, Sutarga I, Pinatih G. Risk factors of attention deficit hyperactivity disorder (adhd) among children in Denpasar. DyscoverSys. 2015;3(1):35-9.

6. Spaniardi AM, Greenhill LL, Hechtman LI, McGough JJ. Attention-deficit disorders. In: Sadock BJ, Sadock VA, Ruiz $\mathrm{P}$, editors. Kaplan \& Sadock's Comprehensive Textbook of Psychiatry (10th ed). Philadelphia: Lippincont William \& Wilkins, 2017

7. American Psychiatric Association. Diagnostic and statistical manual of mental disorders (DSM-V). Washington DC, 2013; p. 59-65.

8. American Psychiatric Association. Diagnostic and statistical manual of mental disorders (DSM-IV). Washington DC, 2000; p. 78-85.

9. Donovan GH, Michael YL, Gatziolis D, Mannetje A, Douwes J. Association between exposure to the matural environment, rurality, and attentiondeficit hyperactivity disorder in children in New Zealand: linkage study. Lancet Planetary Health. 2019;3(5):e226-34.

10. Pelsser LM, Frankena K, Toorman J, Rodrigues PR. Diet and ADHD, reviewing the evidence: a systematic review of meta-analyses of double-blind 
placebo-controlled trials evaluating the efficacy of diet interventions on the behavior of children with ADHD. PLoS ONE. 2017;12(1):e0169277.

11. Wilens TE, Spencer TJ. Understanding Attention deficit/hyperactivity disor-der from childhood to adulthood. NIH Public Access.2010;122(5):97-109.

12. Yu CJ, Du JC, Chiou HC, Feng CC, Chung MY, Yang W, et al. Sugar-sweetened beverages consumption is adversely associated with childhood attention deficit/hyperactivity disorder. Int $\mathbf{J}$ Environ Res Public Health. 2016;13(7):678.

13. Russell P. Children 'exceed sugar consumption limit by age 10'. 2019 [cited 2019Sept20]. Available from: https: //www.medscape.com/viewarticle/9068 27

14. Park S, Cho SC, Hong YC, Oh SY, Kim JW, Shin MS, et al. Association between dietary behaviors and attention-deficit/ hyperactivity disorder and learning disabilities in school-aged children. Psychiatry Research. 2012;198(3):46876.

15. Kim Y, Chang H. Correlation between attention deficit hyperactivity disorder and sugar consumption, quality of diet, and dietary behavior in school children. Nutr ResPract. 2011;5(3):236-45.

16. American Academy of Child \& Adolescent Psychiatry. Peer Pressure. 2018 [cited 2019 Nov 25]. Available from:
https://www.aacap.org/AACAP/Familie s_and_Youth/Facts_for_Families/FFFGuide/Peer-Pressure-104.aspx

17. Lalusu R, Kaunang T, Kandou J. Hubungan gangguan pemusatan perhatian dan hiperaktivitas dengan prestasi belajar pada anak SD Kelas 1 di Kecamatan Wenang Kota Manado. e-CliniC. 2014; 2(1):1-5.

18. Cornejo JW, Osio O, Sanchez Y, Carrizosa J, Sanchez G, Grisales H, Castillo-Parra $\mathrm{H}$, Holguin J. Prevalence of attention deficit hyperactivity disorder in Colombian children and teenagers. Revista de neurologia. 2005;40(12): 716-22.

19. Yoo HI, Cho SC, Kim BN, Kim SY, Shin MS, Hong KE. Psychiatric morbidity of second and third grade primary school children in Korea. Child psychiatry and human development. 2005;36(2):21525.

20. Tandon M, Pergika A. Attention Deficit Hyperactivity Disorder. Child and Adolescent Psychiatric Clinics of North America. 2017;26(3):523-38.

21. Lyon M, Murray M. Attention Deficit Hyperactivity Disorder. In: Pizzorno J, Murray M. Textbook of Natural Medicine (4th ed). Churchill Livingstone, 2013; p. 1252-59.

22. Azadbakht L, Esmaillzadeh A. Dietary patterns and attention deficit hyper-activity disorder among Iranian children. Nutrition. 2012;28(3):242-9. 